\title{
FUSOGENIC LIPOSOME FOR THE TREATMENT OF FUNGAL MENINGITIS: AN OVERVIEW
}

\author{
IRENE SUSAN ALEX, JENEETTA JOSE, RAHUL R, ANJU GOPAL, ANU PRIYA*
}

Department of Pharmaceutics, Amrita School of Pharmacy, Amrita Institute of Medical Sciences and Research Centre, Amrita Vishwa Vidyapeetham, Kochi, Kerala, India. Email: anupriya@aims.amrita.edu

Received: 23 April 2018, Revised and Accepted: 11 August 2018

\begin{abstract}
Fungal meningitis is an infection which is caused by fungus which spreads through the blood to the spinal cord. People with weakened immunity get this disease easily like persons with AIDs, etc. To make sure the disease is fungal meningitis, a sample is taken from the cerebrospinal fluid and it is sent to the laboratory. Usually, fungal meningitis is not mediated from person to person, but it is caused when a fungi are inhaled from the surrounding and spread into the blood to the central nervous system. Normally medications such as vaccines, IV, and oral suspensions are given to the people for curing fungal meningitis. Commonly used drugs are Amphotericin B and fluconazole oral suspension. Amphotericin B is an antifungal, antiprotozoal, and hydrophobic drug. However, these drugs cannot give a directly as medication therapy for the patients, because it offers toxic effect and side effects, absorption rate is slower, and crossing the blood-brain barrier (BBB) is getting difficult. Adverse effects can be minimized with the application of nanotechnology. Therefore, in human medical services, the availability of molecular nanotechnology will provide rapid progress. Nanoparticle (NP) systems help to improve the solubility of poorly water-soluble drugs which has been explained using Noyes-Whitney equations. Nanoparticles offers several advantages as a drug delivery system, such as better drug bioavailability, reduction of dosing frequency enables them for the betterment of diseases, can cross the BBB, and it is very cost-effective. Types of NP include polymeric NP, carbon nanotubes, metallic structures, nanocrystals, and fusogenic liposomes. Fusogenic liposomes are a peculiar class of phospholipid vesicles. The fusogenic liposomes can deliver encapsulated NP into the targeted sites and also can cross the BBB. On comparing with cationic liposomes, fusogenic liposomes are more effective as well as rapid in the drug delivery.
\end{abstract}

Keywords: Fungal meningitis, Nanotechnology, Liposomes, Fusogenic liposomes.

(C) 2018 The Authors. Published by Innovare Academic Sciences Pvt Ltd. This is an open access article under the CC BY license (http://creativecommons. org/licenses/by/4. 0/) DOI: http://dx.doi.org/10.22159/ajpcr.2018.v11i12.26852

\section{INTRODUCTION}

Among different types of fungal infections, one of the types is fungal meningitis. Fungal meningitis is caused due to the inhalation of fungus spores or localized colonization of the skin. Cryptococcus fungus is the main causative organism of fungal meningitis; it is also caused by other organisms. The organisms are generally breathed in and afterward spread into the blood and to the focal sensory system yet it is not spread starting with one individual then onto the next [1]. The growths can likewise be specifically embedded into the focal sensory system by medicinal methods or can be entered from a tainted site close to the focal sensory system which can cause meningitis. Any treatment that may debilitate the insusceptible framework may prompt high hazard components of contagious meningitis. The other hazard factors incorporate surgical methods that are managed with no sterility and will acquaint the growths with the focal anxious. Cerebral pain, solid neck, queasiness, heaving, photophobia, and adjusted mental status are its primary side effects. This is diagnosed by blood and culture of cerebrospinal fluid. The most effective thing to protect children from meningitis is to provide vaccines that protect against most forms of meningitis and septicaemia [2]. Commonly IV antifungal drugs and oral suspensions such as fluconazole and Amphotericin B drugs are given for this treatment. Different drug delivery systems have been developed with the help of nanoparticles (NPs) [3].

\section{PATHOGENESIS}

The key step for a pathogen to infect the brain and cause meningitis is to cross the blood-brain barrier (BBB), an interface that separates the peripheral circulation and central nervous system [4].

\section{BASIC PATHOLOGY OF FUNGAL MENINGITIS [5]}

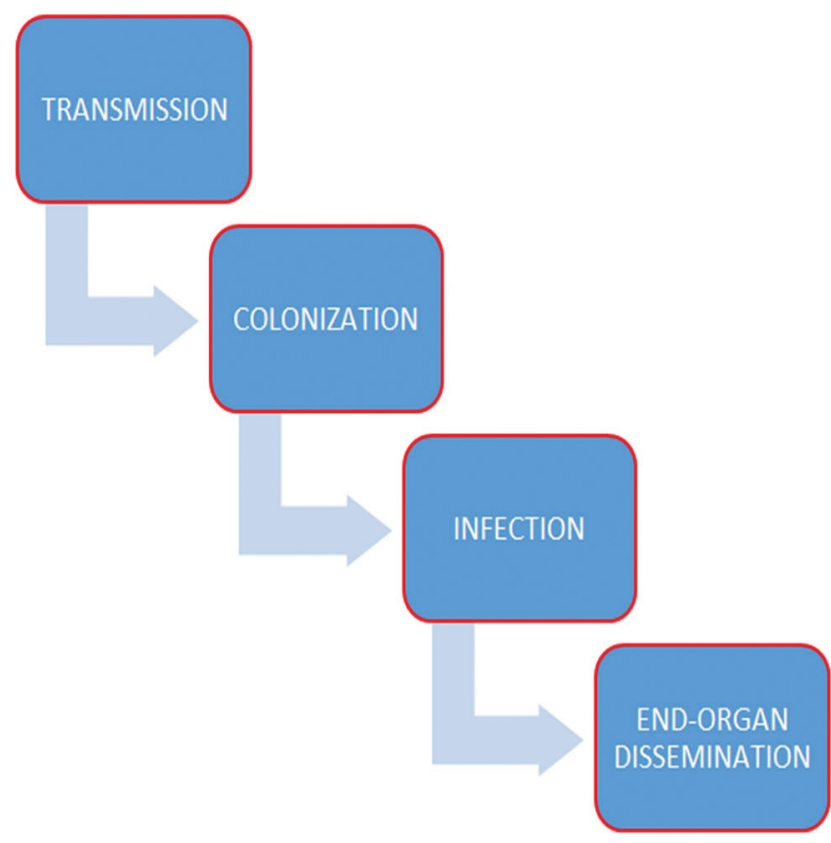




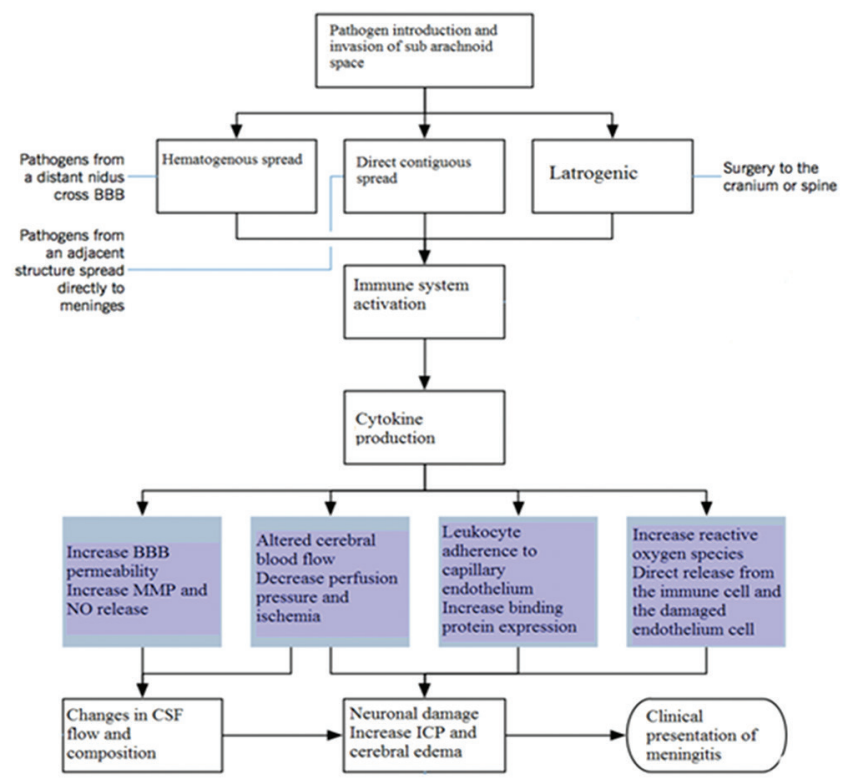

TREATMENTS

A lumbar cut that is spinal tap is utilized to analyze meningitis. Among this test, a specimen of cerebrospinal liquid is expelled from your spine and tried. Antifungal medicines are utilized to treat this type of meningitis. Intravenous (IV, through a vein) treatment with Amphotericin B is the most widely recognized treatment utilized. It is often joined with an oral antifungal medicine called 5-flucytosine. Other drugs which are used for this treatment are fluconazole oral, Abelcet IV, Diflucan oral, fluconazole in sodium chloride IV, fluconazole in dextrose IV, Vfend, Ancobon, IV fluconazole, intrathecal miconazole, and so on. On comparing these drugs, we could find that bioavailability and more effectiveness are given by amphotericin B. Hence, to achieve rapid effectiveness in less time, we can convert this Amphotericin B into a nano form. For intracerebral fungal infection OX26-modified AMBloaded NP were used. Amphotericin B act by the system, in which it ties to the sterol in the layer of sensitive fungi which builds the membrane permeability. The toxicity of this compound is due to the non-specificity and binding of the mammalian cell cholesterol.

Recently, the first preparation of Amphotericin B (AmBisome) as liposome had passed every single clinical trial, and now, it is utilized for the treatment of fungal infections as well. Liposomal Amphotericin $\mathrm{B}$ by latently focusing on the liver and spleen decreases the renal and general danger at typical dosage yet renal toxicity shows up when the medication is given at raised dose because of the saturation of liver and spleen macrophages.

IV Amphotericin B causes important pharmacodynamic interactions through additive nephrotoxicity and myelotoxicity and might increase the cardio tonicity of other drugs because of amphotericin-induced hypokalemia. Lipid formulations of amphotericin Bare less nephrotonic than non-lipid formulation. Orally administered Amphotericin B is not absorbed systemically. The lipid formulation of Amphotericin B such as liposomal Amphotericin B at doses of 4-6 mg/kg/day has comparable efficacy than conventional Amphotericin B at a dose of $0.7 \mathrm{mg} / \mathrm{kg}$.

There are two formulations of amphotericin:

1. Standard (conventional)

2. Lipid-based.

Amphotericin- B bind to ergosterol in fungal cell membrane affecting its integrity by forming spores and therefore cell death. Nystatin, the other polyene is only used topically because of toxicity associated with systemic use. On converting the Amphotericin B into a nanoform, we are enhancing the effectiveness of the drug that helps to cure this disease.
Fluconazole is another drug used in fungal meningitis. It is resistant for Candida glabrata fungi. Its $11 \%$ of the dose is excreted through urine as metabolite. Fluconazole can be taken with or without food. They are available in different dosage forms. Bioavailability of this drug is in the form of oral suspension. Sometimes, it can cause several allergic reactions, which can be identified by symptoms such as shortness in breathing and nausea [6].

Fluconazole is a highly sensitive inhibitor which is having an enzyme lanosterol 14-alpha-methylase that depends on fungal cytochrome p450. This enzyme is used to convert lanosterol to ergosterol. The subsequent loss of normal sterols combines with the accumulation of 14-alpha-methyl sterols in fungi and which may be responsible for the fungistatic activity of the fluconazole. Using these drugs provides a toxicity in our systemic systems as well as provides more time for the absorption of the drugs. Hence, we can use these drugs along with nanotechnology.

One of the fundamental therapeutic uses of the nano medication is that it tries to convey the most important arrangement of research apparatuses and clinically valuable gadgets for the not so distant future. Utilizing NP nanotechnology has given the possibility of conveying medications to the particular cells. Advantage of utilizing nanoscale in therapeutic advancements is that Littler devices are less intrusive and can be embedded inside the body, and also biochemical response times are substantially shorter. The capacity of medication conveyance through nano solution depends on:

a. Efficient exemplification of the medication

b. Successful delivery of medication to the focused region of the body c. Successful arrival of the medication.

NPs can be used in the combination therapy for decreasing antibiotic resistance. It is also used to circumvent multidrug-resistance mechanism. One of the main advantages of nanomedicine is that unsolved medical problems such as cancer are getting benefited by this technology.

Disadvantages of nanomedicine are as follows:

1. Lack of knowledge about the effect of NP on biochemical pathways and in the processes of the human body.

2. Scientists are mainly concerned about the toxicity, characterization, and exposure pathways associated with nanomedicine that might pose a serious threat to the human beings as well as to the environment.

\section{NANOTECHNOLOGY AND ITS ELEMENTS}

\section{NPs}

NPs are particles that can be orchestrated synthetically and organically. It extends between 1 and $100 \mathrm{~nm}$. They basically happen as strong colloidal structures. In nanotechnology, a molecule is characterized as a little question that carries on in general unit regarding its vehicle and properties [7]. As NPs are sufficiently little to bind their electrons and deliver quantum impacts, they regularly have sudden optical properties [8]. On contrasting gold pieces and gold NPs, gold NPs soften at much lower temperatures $\left(\sim 300^{\circ} \mathrm{C}\right.$ for $2.5 \mathrm{~nm}$ sizes $)$ than the gold sections $\left(1064^{\circ} \mathrm{C}\right)$. Materials made out of NPs have considerably higher assimilation of sun-powered radiation than it is in thin movies of persistent sheets of material.

There are diverse techniques for making NP, which incorporate gas buildup, steady loss, synthetic precipitation, pyrolysis, and aqueous amalgamation. In whittling down technique, full-scale or small-scale particles are grounded in a ball process, planetary ball process, or some other size-decreasing system. After the procedure, we get a subsequent molecule which is air grouped to recuperate NP. In pyrolysis strategy, a vaporous forerunner (fluid or gas) is constrained through a hole at high weight and consumed. After the procedure, we get a subsequent strong (a variant of residue) which is air arranged to recuperate oxide particles from the result gasses. On contrasting and customary 
pyrolysis and single essential particles, conventional pyrolysis regularly brings about totals and agglomerates as opposed to single essential particles. Ultrasonic spout shower pyrolysis then again helps in keeping agglomerates from framing. NP with higher surface area increase the poorly water-soluble drugs. NP in liquid suspension produces more homogenous product with more shelf life. Delivery strategies include injection, oral delivery, delivery to brain, and gene therapy. NPs avoid the risk of embolism associated with IV administration. Targeting tumors and inflamed vascular regions are possible with their IV administration. Oral delivery systems formulated with NP enhanced with the bioavailability for poorly water-soluble drugs and systemic targeting through circulatory uptake from the intestine. Ocular delivery using topical system is challenging due to tear flow, blinking, and multiple tissue. NP is found to possess improved accessibility to deep ocular tissues; thereby, it maintains improved residence time in eye. In drug delivery to the brain, the highly selective BBB can be made of permeable with surface modified NP. These NPs are able to carry drugs to BBB.

Therapeutically utilized as:

- Liposome

- Dendrimer

- Iron oxide NP

- Polymer tranquilize conjugate

- Polymeric NP.

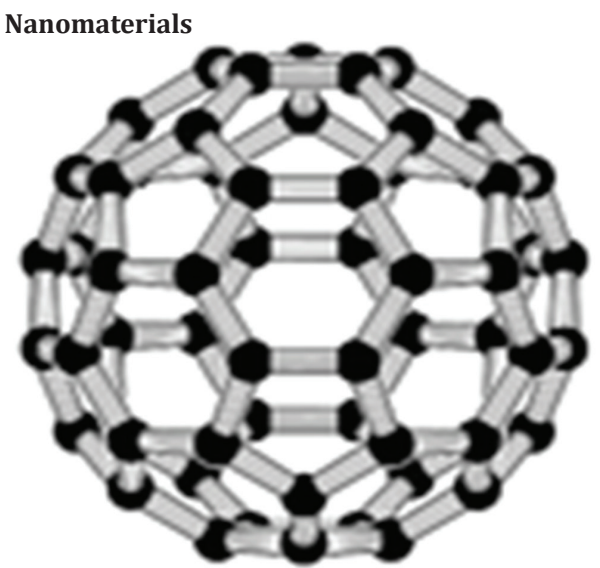

\section{Natural nanomaterials}

Organic frameworks are frequently included with characteristic and useful nanomaterials [9]. A few cases of normal natural nanomaterials incorporate the structure of foraminifera (mainly chalk) and infections (protein and capsid), the wax gems covering a lotus or nasturtium leaf, creepy crawly and bug vermin silk, the blue tone of tarantulas, the "spatula" on the base of gecko feet, some butterfly wing scales, regular colloids, for example, drain, blood, horny materials (skin, paws, noses, quills, horns, and hair), hair paper, cotton, nacre, corals, and even our own bone grid, and so forth. A characteristic inorganic nanomaterial happens through precious stone development in the assorted synthetic states of the world's outside. For instance, dirt showcases complex nanostructures because of anisotropy of their hidden precious stone structure and volcanic action can offer ascent to opals, which are an example of a normally happening photonic gem due to their nanoscale structure. Flames speak to, especially, complex responses and can deliver colors, concrete, seethed silica, and so on

Nanomaterials are blended by two fundamental strategies. Right off the bat by bottom-up technique besides by top-up strategy. There likewise exists engineered strategy for the planning of nanomaterials however should display a control over the size which ranges from $\sim 1$ to $100 \mathrm{~nm}$ then no one but it can accomplish its properties.

\section{Bottom-up methods}

This strategy includes the gathering of particles or atoms which are taken into nanostructured exhibits. Here, the crude material sources can be in type of gasses, fluids, or solids. Base techniques by and large partitioned into two classes: Tumultuous and controlled procedures.

\section{Chaotic processes}

This procedure includes lifting the particles or atoms to a tumultuous state and after that all of a sudden changing the conditions in order to make that state unsteady. Cases of chaotic processes are laser removal, exploding wire, arc, flame pyrolysis, combustion, and precipitation blend procedures.

\section{Controlled processes}

This procedure includes lifting the particles or atoms to a tumultuous state and after that all of a sudden changing the conditions in order to make that state unsteady. Cases of chaotic processes are laser removal, exploding wire, arc, flame pyrolysis, combustion, and precipitation blend procedures.

\section{Nanocapsules}

It is mainly made up of non-toxic polymer and is made up of nanoscale shells. They are sac systems manufactured from a chemical compound membrane that encapsulates an inner liquid core at the nanoscale. Nanocapsules have several uses as well as medical applications for drug delivery, food sweetening, nutraceuticals, and additionally for self-healing materials. The advantages of encapsulation strategies square measure the protection of those substances within the adverse surroundings, for controlled unleash, and for preciseness targeting $[10,11]$ Nanocapsules will doubtless be used as associate magnetic resonance imaging-guided nanorobots or nanobots. The traditional size of a nanocapsule used for varied applications ranges from 10 to $1000 \mathrm{~nm}$. However, counting on the preparation and use of the nanocapsule, the dimensions are going to be a lot of specific. The structure of a nanocapsule consists of nanosac system that is shaped in a very core-shell arrangement. The shell of a nanocapsule is framed of a compound layer or a covering. The sort of polymers utilized is of perishable polyester because of nanocapsule square measure normally used in organic frameworks. Chiefly polymers are used Nanocontainer development square measure Poly-e-caprolactone, poly (lactide), and poly (lactide-co-glycoside). Distinctive polymers grasp nacked poly (methacrylic corrosive) and poly ( $\mathrm{N}$-vinylpyrrolidone). Comparing with manufactured polymers and present polymers, counterfeit polymers have checked to be a considerable measure of unadulterated and steady. They are normally most prevalent for the advancement of nanocapsules. Some present polymers such as chitosan, gelatin, sodium alginate, and egg whites square measure used in some medication conveying nanocapsules. Diverse nanocontainer shells grasp liposomes with polysaccharides and saccharides. Polysaccharides and saccharides square measure utilized because of their non-harmfulness and biodegradability. The center of a nanocapsule comprises of an oil substance specialist that is particularly organized the picked tranquilize inside the compound film. The specific oil that is utilized ought to be amazingly dissolvable with the medication, and non-lethal once used in a natural environment. The oil-medicate emulsion ought to have low dissolvability with the compound layer to affirm that the medication is conveyed all through the framework appropriately and be released at the right time and site. Once the right emulsion is gotten, the medication should be consistently spread all through the entire inner depression of the compound film. These procedures depend on the physiochemical properties of the center material, the divider material, and furthermore the required size.

The most well-known routes that to give nanocapsule are nano precipitation, emulsion-dissemination, and dissolvable vanishing systems. Nano precipitation method is, moreover, called removal strategy. Inside the nanoprecipitation procedure, nano cases are formed by influencing a colloidal arrangement between the 2 and isolate stages. The natural part comprises of an answer and a blend of natural solvents though the parallel compound part comprises of a blend of non-solvents that structure a surface film. The natural part is gradually infused inside the paired compound part that is then unsettled to make the colloidal arrangement. Once the colloidal arrangement is influenced, it will to by 
upset until the nanocontainers started to make. The scale and type of the nanocontainer rely on the speed of the infusion in conjunction with the speed of disturbance.

Another common way to prepare nanocapsules is the emulsion diffusion method. This method consists of three phases:

- Organic phase

- Aqueous phase and

- Dilution phase.

In this methodology, the organic section is additional to the binary compound section below conditions of high agitation that kind of an emulsion. Throughout this method, water is additional to the emulsion that causes the solvent to diffuse [12]. The results of this emulsion diffusion methodology are nanocapsule formation.

Another effective methodology used for the preparation of nanocapsule is solvent evaporation methodology. During this methodology, single or double emulsions square measure fashioned from solvents and square measure would not to formulate a NP suspension. High-speed blend or ultrasonication is employed to create tiny particle size within the NP suspension. Once the suspension is stable, the solvents square measure gaseous mistreatment either continuous magnetic stirring at temperature or by reducing the close pressure.

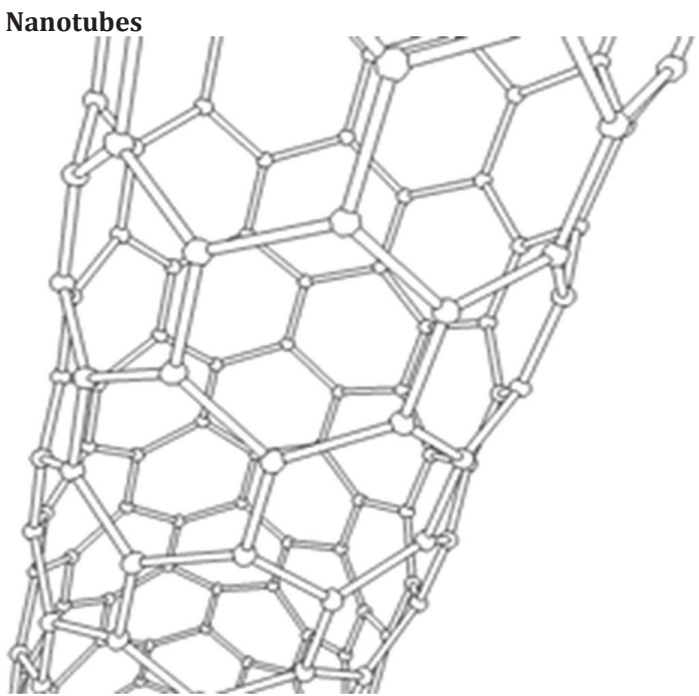

It is a tube-like structure of a nanometer scale which is also known as NP. They are large enough channels compared to other NP. The first discovered nanotubes are carbon nanotubes.

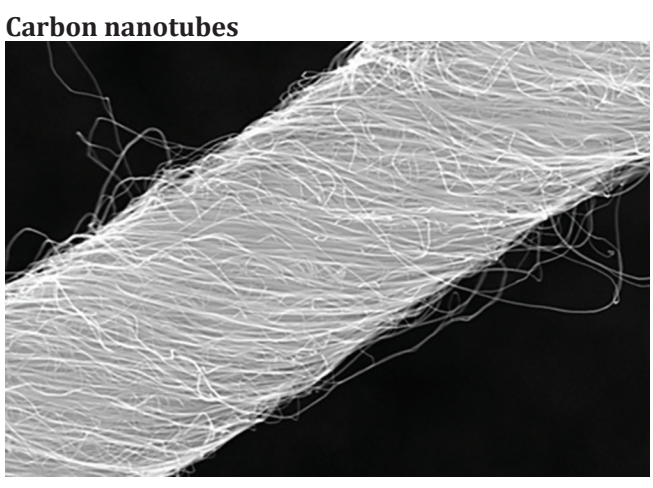

Carbon nanotubes are carbons that are capable of forming many allotropes due to its valency with a cylindrical nanostructure [13]. Nanotubes have extraordinary thermal conductivity mechanism. Carbon nanotubes are carbons that are fit for framing numerous allotropes because of its valency with a round and hollow nanostructure. Nanotubes have exceptional warm conductivity instrument and electrical properties. They discover applications in different auxiliary materials such as polished ash, golf clubs, auto parts. or Damascus steel. According to quantum chemistry, the chemical bonding in nanotubes is described through orbital hybridization.

There are different types of carbon nanotubes, they are as follows:

- Single-walled carbon nanotubes: Its diameter is about $1 \mathrm{~nm}$. It is one of the important varieties of carbon nanotubes.

- Multiple-walled carbon nanotubes: It consists of multiple moved layers of graphene. These can be described by two models: Russian Doll model and material model.

- Double-walled carbon nanotubes: It forms a special class of nanotube. They find applications in various structural materials such as baseball bats, golf clubs, car parts, or Damascus steel.

Carbon nanotubes contain different properties which include:

- Mechanical properties

- $\quad$ Electrical properties

- Optical properties

- Thermodynamic properties.

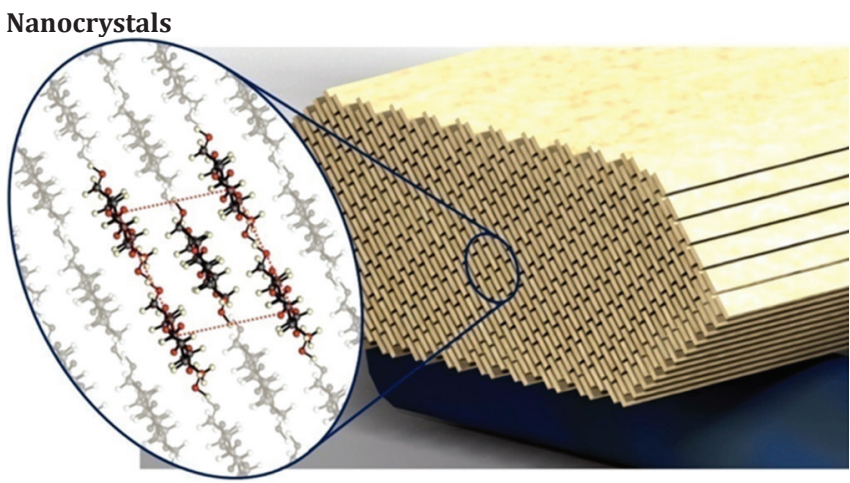

Nanocrystals are NP containing $<100 \mathrm{~nm}$. It is made up of atoms either which is in a single or polycrystalline arrangement. They are layered, and it is applied to flexible substrates to produce solar panels. Nanocrystals, which can be done by converting it into nanosized particles. It can then be suspended into liquids, pressed into tablets, and made into powder.

They are used in the manufacture of filters that refine crude oil into diesel fuel. Possible future uses are production of hydrogen, removal of pollutants and toxins, medical imaging, drug manufacture, and protein analysis.

Nanocrystals can be synthesized by traditional method. It involves molecular precursor that is typical metal salts and a source of the anion. Semiconducting nanomaterials have features such as chalcogenide and pnictides. These elements are from silylated derivatives such as bis (trimethylsilyl) sulfide ( $\mathrm{S}\left(\mathrm{SiMe}_{3}\right)_{2}$ and Tris (trimethylsilylphosphine $\left(\mathrm{p}\left(\mathrm{SiMe}_{3}\right)_{3}\right)$. Surfactants are used to solubilize the growing nanocrystals in some procedures. Nanocrystals may exchange their elements with reagents through atomic diffusion.

\section{Nanogels}

A nanogel is a NP which is composed of hydrogel. They are composed of polymers which are chemically or physically cross-linked [14-16].

\section{Liposome}

A liposome is a round vesicle which is having number $<1$ lipid bilayer. By upsetting organic films (for example, by sonification), liposomes can be readied. Liposomes are for the most part made out of phospholipids, particularly phosphatidylcholine; however, it might likewise incorporate different lipids, for example, egg phosphatidylethanolamine, so they can be sufficiently long as they are good with the lipid bilayer structure [17,18]. A liposome comprises of surface ligands for appending to the unfortunate tissue. Liposome can likewise be focused to lungs by covering vesicle with o-stearoyl amylopectin, poly oxylethylene, or mono-sialogangliocyte [19]. The epitome of hostile to 
tubercular operator such as isoniazid and rifampicin in lung focused on liposome adjusts the lethality and enhances the productivity of these medications [20]. They have good entrapment efficiency than others. These are the most extensively developed nanocarrier for novel and the targeted therapy. They have both determination and additionally remedial property. They have low poisonous quality. They are usually made out of at least one amphiphilic phospholipid bilayer film that can capture both hydrophilic and hydrophobic medications.

The real sorts of liposomes are as follows:

- The multilamellar vesicle - with a few lamellar stage lipid bilayers,

- The small unilamellar liposome vesicle (SUV) - with one lipid bilayer,

- The extensive unilamellar vesicle, and

- The cochleate vesicle.

A less alluring structure is multivesicular liposomes in which one vesicle contains at least one little vesicles [21]

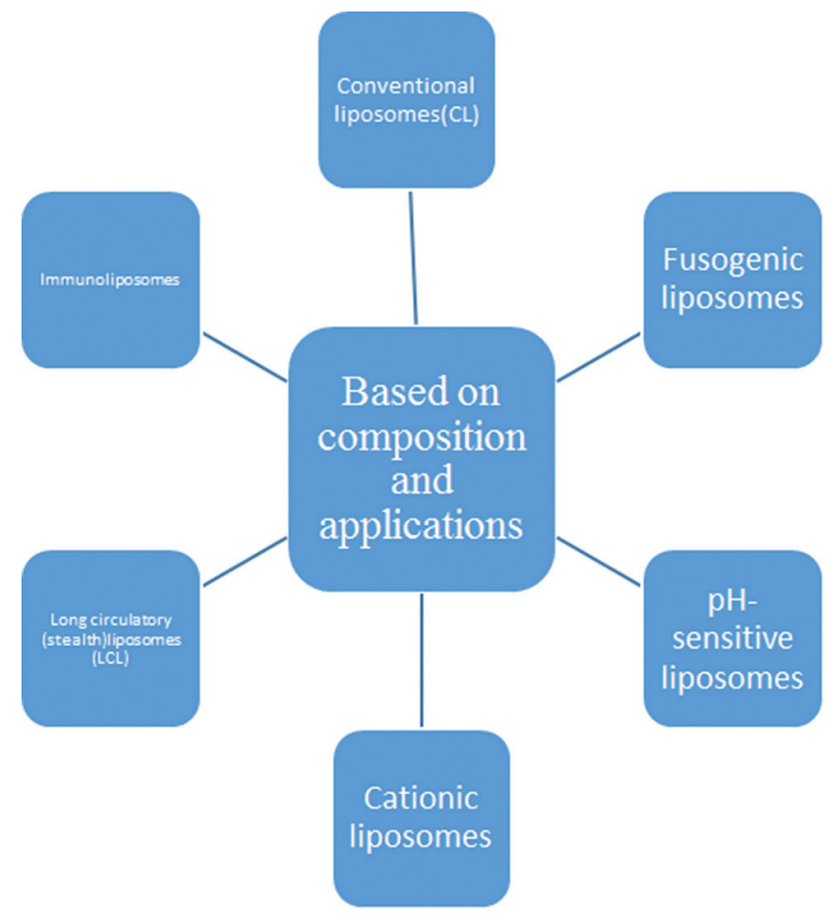

\section{Drug delivery system}

Liposomes with a little distance across (50-100 nm) and additionally extensive breadth experience free dissemination through the blood-brain barrier (BBB). It is conceivable that a SUVs which are coupled to cerebrum medicate transport vectors can be transported through the BBB by receptor interceded or absorptive intervened transcytosis. Likewise, to experience absorptive intervened endocytosis into the cells, cationic liposomes were created as of late which demonstrated these structures. The vehicle of substances through BBB by liposomes was broadly examined. The imperative discovering issues from their examinations are that the expansion of the sulfatide (a sulfur ester of galactocerebroside) to liposome synthesis expands their capacity to cross the BBB [21]. Wangetal finished up with his report that liposomes covered with the mannose achieve the cerebrum tissue and the mannose coat help the vehicle of the stacked medication through BBB. By giving fundamentally course of organization, the neuropeptides, leuenkephalin, and mefenkephalinkyoforphin regularly do not cross the BBB [22]. The energizer amitriptyline typically infiltrates the $\mathrm{BBB}$, because of adaptability of this strategy. NPs were manufactured by utilizing different stabilizers. At the point when the substance was adsorbed onto the NP and covered or molecule settled with polysorbate 85 , it was discovered that amitriptyline level has altogether improved in the cerebrum [23]
Liposomes can interact with cells by five different mechanisms [24].

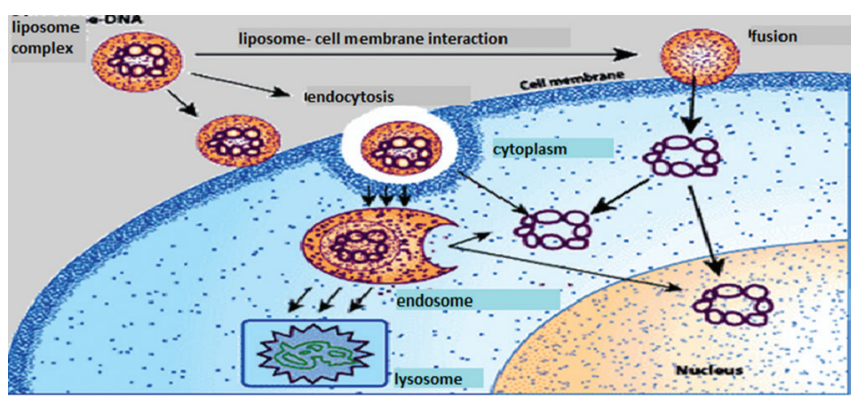

\section{Fusogenic liposomes}

Fusogenic liposomes are a peculiar class of phospholipid vesicles [25]. At several environmental conditions, the liposomes having lipids that promote the [26] destabilisation of fungal membrane are called fusogenic liposome or pH-sensitive liposomes [27]. Afusogenic liposome is utilized for conveying a liposome captured compound into the cytoplasm of a focused on cell [28]. The liposomes have an external surface which is of a covering with artificially releasable hydrophilic polymer chains that shield hydrophobic polymers on the liposome external surface. Arrival of the hydrophilic polymer chains uncovered the hydrophobic polymers for the collaboration with external cell films of the objective cells to advance the combination of the liposome with the focused on cells $[29,30]$. This is one of the techniques utilized for the organization to convey a compound to the objective cells and is likewise a strategy for choosing appropriate hydrophobic polymers for the utilization in the arrangement. Fusogenic liposomes can convey embodied NP into the focused on locales and furthermore can cross the BBB [31-35].

\section{CONCLUSION}

Hereby, we can conclude that fungal meningitis is a fungal infection which is caused by a fungus spreading through the blood into the spinal cord and to the brain. People with weak immunity have this disease. Drugs on coating with nanopolymers are used to deliver the drugs. They can be easily crossed through the BBB. On converting the drugs into a nano form, it makes easy for the absorption as well as for the fast recovery. Liposomes are used as the nanocarriers for the drug delivery. They are composed of phospholipids, which have the capacity to form structures with barrier properties. They became popular with their efficiency, biocompatibility, and non-immunogenicity and also enhanced the solubility of chemotherapeutic agents. Fusogenic liposomes can deliver encapsulated NP into the targeted sites and also can cross the BBB. One of the rare characteristics for fusogenic liposomes is that they can intertwine with an assortment of mammalian cell membranes and convey their substance, which are exemplified in liposomes, into the cytoplasm. Fusogenic liposomes can convey different macromolecules, for example, plasmids, oligonucleotides, or NP, and in addition, they are cytosolic conveys delivers. On comparing with cationic liposomes, fusogenic liposomes are more effective as well as rapid in drug delivery.

\section{AUTHORS' CONTRIBUTIONS}

These authors contributed equally to this work.

\section{CONFLICTS OF INTEREST}

The authors have declared no conflicts of interest.

\section{REFERENCES}

1. Honda H, Warren DK. Central nervous system infections: Meningitis and brain abscess. Infect Dis Clin North Am 2009;23:609-23.

2. Venkatakrishnan K, von Moltke LL, Greenblatt DJ. Effects of the antifungal agents on oxidative drug metabolism: Clinical relevance. Clin Pharmacokinet 2000;38:111-80.

3. Mohammed N, Rejinold NS, Mangalathillam S, Biswas R, Nair SV, Jayakumar R, et al. Fluconazole loaded chitin nanogels as a topical 
ocular drug delivery agent for corneal fungal infections. J Biomed Nanotechnol 2013;9:1521-31.

4. Walker R, Whittlesea C. Clinical Pharmacy and Therapeutics. $5^{\text {th }}$ ed. London: Churchill Livingstone; 2011.p. 661.

5. Mendez-Vilas A. Science against microbial pathogens: Communicating current research and technological advances. Current 2011;2:1-691.

6. Porter RS, Kalpan JL. The Merck Manual of Diagnosis and Therapy. $19^{\text {th }}$ ed. London: Merck and Co., Inc; 1930. p. 1321-2.

7. Nagavarma BV, Hemant KS, Ayaz A, Vasudha LS, Shivakumar HG. Different techniques for preparation of polymeric nanoparticles- a review. Asian J Pharm Clin Res 2012;5:16-23.

8. Chien S. Intracellular ATP delivery using highly fusogenic liposomes. In: Weissig V, editor. Liposomes: Methods and Protocols. Vol.1: Pharmaceutical Nanocarriers. New York: Springer; 2009. p. 377-91.

9. Ezhilarasi PN, Karthik P, hhanwal N, Anandharamakrishnan C. Nanoencapsulation techniques for food bioactive components: A review. Food Bioproc Technol 2012;6:628-47.

10. Mora-Huertas CE, Fessi H, Elaissari A. Polymer-based nanocapsules for drug delivery. Int J Pharm 2010;385:113-42.

11. Olga S, Yan Y, Yajun W, Frank C. Shape-dependent cellular processing of polyelectrolyte capsules. ACS Nano 2013;7:522-30.

12. Ren WH, Chang J, Yan CH, Qian XM, Long LX, He B, et al. Development of transferrin functionalized poly(ethylene glycol)/ poly(lactic acid) amphiphilic block copolymeric micelles as a potential delivery system targeting brain glioma. J Mater Sci Mater Med 2010;21:2673-81.

13. Takeuchi K, Hayashi T, Kim YA, Fujisawa K, Endo M. The state-ofthe-art science and applications of carbon nanotubes. Nano J Ifmo Ru 2014;5:15.

14. Mangalathillam S, Rejinold NS, Nair A, Lakshmanan VK, Nair SV, Jayakumar R, et al. Curcumin loaded chitin nanogels for skin cancer treatment via the transdermal route. Nanoscale 2012;4:239-50.

15. Singh SS, Roy A, Lee B, Banerjee I, Kumta PN. Synthesis, characterization, and in-vitro cytocompatibility of amorphous $\beta$-tricalcium magnesium phosphate ceramics. Mater Sci Eng C Mater Biol Appl 2016;67:636-45.

16. Kabanov AV, Vinogradov SV. Nanogels as pharmaceutical carriers: Finite networks of infinite capabilities. Angew Chem Int Ed Engl 2009;48:5418-29.

17. Nakanishi M, Mizuguchi H, Ashihara K, Senda T, Eguchi A, Watabe A, et al. Gene delivery systems using the Sendai virus. Mol Membr Biol 1999;16:123-7.

18. Yoshikawa T, Imazu S, Gao JQ, Hayashi K, Tsuda Y, Okada N, et al. Non-methylated cpG motif packaged into fusogenic liposomes enhance antigen-specific immunity in mice. Biol Pharm Bull 2006;29:105-9.

19. Deshpande PP, Biswas S, Torchilin VP. Current trends in the use of liposomes for tumor targeting. Nanomedicine (Lond) 2013;8:1509-28.

20. Wiener N, Lieb L. Medical Applications of Liposome. Oxford: Elsevier; 1998.

21. Kunisawa J, Masuda T, Katayama K, Yoshikawa T, Tsutsumi $Y$, Akashi M, et al. Fusogenic liposome delivers encapsulated nanoparticles for cytosolic controlled gene release. J Control Release 2005;105:344-53.

22. Freise J, Magerstedt P. Liposomes as a Drug Carrier. Stuttgart: George ThiemeVerlag; 1986.

23. Ranade VV. Drug delivery systems 1 . Site-specific drug delivery using liposomes as carriers. J Clin Pharmacol 1989;29:685-94.

24. Boomer JA, Qualls MM, Inerowicz HD, Haynes RH, Patri VS, Kim JM, et al. Cytoplasmic delivery of liposomal contents mediated by an acid-labile cholesterol-vinyl ether-PEG conjugate. Bioconjug Chem 2009;20:47-59.

25. Meers PR, Shangguan T, Cabral-Lilly D, Ahl P, Erukulla R, Janoff A. Modular Targeted Liposomal Delivery Systems. US: US Patent; 2006.

26. Kunisawa J, Nakagawa S, Mayumi T. Pharmacotherapy by intracellular delivery of drugs using fusogenic liposomes: Application to vaccine development. Adv Drug Deliv Rev 2001;52:177-86.

27. Yoshikaw T. Fusogenic liposomes and their suitability for gene delivery. Future Lipidol 2006;1:735-42

28. Karanth H, Murthy RS. PH-sensitive liposomes - principle and application in cancer therapy. J Pharm Pharmacol 2007:59:469-83.

29. Shangguan T, Cabral-Lilly D, Purandare U, Godin N, Ahl P, Janoff A, et al. A novel N-acyl phosphatidylethanolamine-containing delivery vehicle for spermine-condensed plasmid DNA. Gene Ther 2000;7:769-83.

30. Cullis PR, Choi LS, Monck M, Bailey AL. Fusogenic Liposomes. US: US Patent; 2003

31. Simões S, Moreira JN, Fonseca C, Düzgünes N, de Lima MC. On the formulation of $\mathrm{pH}$-sensitive liposomes with long circulation times. Adv Drug Deliv Rev 2004;56:947-65.
32. Li H, Nelson CE, Evans BC, Duvall CL. Delivery of intracellular-acting biologics in pro-apoptotic therapies. Curr Pharm Des 2011;17:293-319.

33. Csiszár A, Hersch N, Dieluweit S, Biehl R, Merkel R, Hoffmann B, et al. Novel fusogenic liposomes for fluorescent cell labeling and membrane modification. Bioconjug Chem 2010;21:537-43.

34. Mustata RC, Grigorescu A, Petrescu SM. Encapsulated cargo internalized by fusogenic liposomes partially overlaps the endoplasmic reticulum. J Cell Mol Med 2009;13:3110-21.

35. Jilsha G, Viswanad V. Nanosponges: A novel approach of drug delivery system. Int J Pharm Sci Rev Res 2013;19:119-23.

36. Karenbaxter A, Preston CL. Stockley's Drug interaction. $10^{\text {th }}$ ed. New York: Marcel Dekker; 2012. p. 210.

37. Grubber SM. Liposome Biophysics Therapeutics. New York: Marcel Dekker; 1987

38. Shim MS, Kwon YJ. Efficient and targeted delivery of siRNA in vivo. FEBS J 2010;277:4814-27

39. Vartholomeos P, Fruchard M, Ferreira A, Mavroidis C. MRI-guided nanorobotic systems for therapeutic and diagnostic applications. Annu Rev Biomed Eng 2011;13:157-84.

40. Michel V, Yoshiharu D, Karl-Heinz H, Michael H, Philip H, Przemyslaw $\mathrm{K}$, et al. Terminology for bio related polymers and applications (IUPAC recommendations 2012. Pure Appl Chem 2012;84:377-410

41. Brian PT, Kathryn W, Weiwei G, Daniel SK, Omid F, Daniel A, et al. Advances in drug delivery. Ann Rev Matr Res 2011;41:1-20.

42. Fuhr O, Dehnen S, Fenske D. Chalcogenide clusters of copper and silver from silyliatedchalcogenide sources. Chem Soc Rev 2013;42:1871-906.

43. Department of Biopharmaceutics, Graduate School of Pharmaceutical Sciences. Suita, Osaka: Osaka University 1-6 Yamadaoka. p. 565-871.

44. Mok KW, Cullis PR. Structural and fusogenic properties of cationic liposomes in the presence of plasmid DNA. Biophys J 1997;73:2534-45.

45. Bencherif SA, Siegwart DJ, Srinivasan A, Horkay F, Hollinger JO, Washburn NR, et al. Nanostructured hybrid hydrogels prepared by a combination of atom transfer radical polymerization and free radical polymerization. Biomaterials 2009;30:5270-8.

46. Cui J, Ren B, Tong Y, Dai H, Zhang L. Synergistic combinations of antifungals and anti-virulence agents to fight against Candida albicans. Virulence 2015;6:362-71.

47. Priyanka R, Bhattacharya S. A review on promising antibiotic therapy by novel delivery system. Asian J Pharm Clin Res 2018;11:5.

48. Chandran PK, Ulagan MP. Antimicrobial and anticancer activity of silver nanoparticles from edible mushroom. Asian J Pharm Clin Res 2017;10:3.

49. Kadian R. Nanoparticles: A promising drug delivery approach. Asian J Pharm Clin Res 2018;11:1

50. Davis S. Drug delivery systems interdisciplinary. Sci Rev 2000;25:175.

51. Couvreur P, Barratt G, Fattal E, Legrand P, Vauthier C. Nanocapsule technology: A review. Crit Rev Ther Drug Carrier Syst 2002;19:99-134.

52. Ringe K, Walz C, Sabel B. Nanoparticle drug delivery to the brain. In: Nalwa, HS, editor. Encylopedia of Nano Science and Nanotechnology. New York: American Scientific Publishers; 2004.

53. Tiwari KB, Rijal B, Ghimire P, Sharma AP. Acute bacterial meningitis in nepal. Nepal Med Coll J 2007;9:100-3

54. Esta LP, Castanedapastor A, Navarrom G, Gcercia-Madero R, Lopez-Cano Gomez M, Ayud-fernandez M. Comparative studies of Staphylococcus aures and Coagulase negative staphylococci in adults. Rev Neurol 2009;48:2-6.

55. Perelshtein I, Applerot G, Perkas N, Guibert G, Mikhailov S, Gedanken A, et al. Sonochemical coating of silver nanoparticles on textile fabrics (nylon, polyester and cotton) and their antibacterial activity. Nanotechnology 2008;19:245705.

56. Bender AR, von Briesen H, Kreuter J, Duncan IB, RübsamenWaigmann H. Efficiency of nanoparticles as a carrier system for antiviral agents in human immunodeficiency virus-infected human monocytes/ macrophages in vitro. Antimicrob Agents Chemother 1996;40:1467-71.

57. Jahanshahi M, Babali Z. Protein nanoparticle: A unique system as drug delivery vehicles. Afr J Biotech 2008;7:4926.

58. Schroeder U, Sommerfeld P, Ulrich S, Sabel BA. Nanoparticle technology for delivery of drugs across the blood-brain barrier. J Pharm Sci 1998:87:1305-7.

59. Christophe LJ, Allémann F, Jaeghere FD, Doelker E, Gurny R. Biodegradable nanoparticles-from sustained release formulations to improved site specific drug delivery. J Control Release 1996;39:339.

60. Alexis F, Pridgen E, Molnar LK, Farokhzad OC. Factors affecting the clearance and biodistribution of polymeric nanoparticles. Mol Pharm 2008;5:505-15.

61. Soppimath KS, Aminabhavi TM, Kulkarni AR, Rudzinski WE. Biodegradable polymeric nanoparticles as drug delivery devices. 
J Control Release 2001;70:1-20

62. Mahapatro A, Singh DK. Biodegradable nanoparticles are excellent vehicle for site directed in-vivo delivery of drugs and vaccines. J Nanobiotechnology 2011;9:55.

63. Panyam J, Labhasetwar V. Biodegradable nanoparticles for drug and gene delivery to cells and tissue. Adv Drug Deliv Rev 2003;55:329-47.

64. Forier K, Raemdonck K, De Smedt SC, Demeester J, Coenye T, Braeckmans K, et al. Lipid and polymer nanoparticles for drug delivery to bacterial biofilms. J Control Release 2014;190:607-23.

65. Tunkel AR, Hartman BJ, Kaplan SL, Kaufman BA, Roos KL, Scheld WM, et al. Practice guidelines for the management of bacterial meningitis. Clin Infect Dis 2004:39:1267-84.

66. Kanra G, Akan O, Ecevit Z, Ceyhan M, Seçmeer G. Microorganisms involved in acute bacterial meningitis in children and the role of haemophilus influenzae. Turk J Pediatr 1996;38:407-12

67. Gray LD, Fedorko DP. Laboratory diagnosis of bacterial meningitis. Clin Microbiol Rev 1992;5:130-45

68. Csiszár A, Csiszar A, Pinto JT, Gautam T, Kleusch C, Hoffmann $\mathrm{B}$, et al. Resveratrol encapsulated in novel fusogenic liposomes activates nrf2 and attenuates oxidative stress in cerebromicrovascular endothelial cells from aged rats. J Gerontol A Biol Sci Med Sci 2015;70:303-13.

69. Mriouah J, Nesbitt RN, Pink D. Fusogenic liposome: A novel therapeutic strategy to efficiently target and destroy prostate cancer. Cancer 2014;2014:821

70. Yoshikawa T, Imazu S, Gao JQ, Hayashi K, Tsuda Y, Okada N, et al. Non-methylated cpG motif packaged into fusogenic liposomes enhance antigen-specific immunity in mice. Biol Pharm Bull 2006;29:105-9.

71. Bartomeu Garcia C, Shi D, Webster TJ. Tat-functionalized liposomes for the treatment of meningitis: An in vitro study. Int J Nanomedicine 2017;12:3009-21.

72. Csiszár A, Hersch N, Dieluweit S, Biehl R, Merkel R, Hoffmann B, et al. Novel fusogenic liposomes for fluorescent cell labeling and membrane modification. Bioconjug Chem 2010;21:537-43.

73. Kleusch C, Hersch N, Hoffmann B, Merkel R, Csiszár A. Fluorescent lipids: Functional parts of fusogenic liposomes and tools for cell membrane labeling and visualization. Molecules 2012;17:1055-73.

74. Kube S, Hersch N, Naumovska E, Gensch T, Hendriks J, Franzen A, et al. Fusogenic liposomes as nanocarriers for the delivery of intracellular proteins. Langmuir 2017;33:1051-9.
75. Leenders AC, Daenen S, Jansen RL, Hop WC, Lowenberg B, Wijermans PW, et al. Liposomal amphotericin B compared with amphotericin B deoxycholate in the treatment of documented and suspected neutropenia-associated invasive fungal infections. $\mathrm{Br} \mathrm{J}$ Haematol 1998;103:205-12.

76. Mills W, Chopra R, Linch DC, Goldstone AH. Liposomal amphotericin $B$ in the treatment of fungal infections in neutropenic patients: A singlecentre experience of 133 episodes in 116 patients. Br J Haematol 1994;86:754-60

77. Ng TT, Denning DW. Liposomal amphotericin B (AmBisome) therapy in invasive fungal infections. Evaluation of United Kingdom compassionate use data. Arch Intern Med 1995;155:1093-8.

78. Boswell GW, Buell D, Bekersky I. AmBisome (liposomal amphotericin B): A comparative review. J Clin Pharmacol 1998;38:583-92.

79. Scarcella A, Pasquariello MB, Giugliano B, Vendemmia M, de Lucia A. Liposomal amphotericin B treatment for neonatal fungal infections. Pediatr Infect Dis J 1998; 17:146-8.

80. Lopez-Berestein G, Bodey GP, Fainstein V, Keating M, Frankel LS, Zeluff B, et al. Treatment of systemic fungal infections with liposomal amphotericin B. Arch Intern Med 1989;149:2533-6.

81. Johnson EM, Ojwang JO, Szekely A, Wallace TL, Warnock DW. Comparison of in vitro antifungal activities of free and liposomeencapsulated nystatin with those of four amphotericin B formulations. Antimicrob Agents Chemother 1998;42:1412-6.

82. Brajtburg J, Powderly WG, Kobayashi GS, Medoff G. Amphotericin B: Current understanding of mechanisms of action. Antimicrob Agents Chemother 1990;34:183-8

83. Brajtburg J, Powderly WG, Kobayashi GS, Medoff G. Amphotericin B: Delivery systems. Antimicrob Agents Chemother 1990;34:381-4.

84. Weber RS, Lopez-Berestein G. Treatment of invasive aspergillus sinusitis with liposomal-amphotericin B. Laryngoscope 1987:97:937-41.

85. Bellocchio S, Gaziano R, Bozza S, Rossi G, Montagnoli C, Perruccio K, et al. Liposomal amphotericin B activates antifungal resistance with reduced toxicity by diverting toll-like receptor signalling from TLR-2 to TLR-4. J Antimicrob Chemother 2005;55:214-22.

86. Chang HI, Yeh MK. Clinical development of liposome-based drugs: Formulation, characterization, and therapeutic efficacy. Int $\mathrm{J}$ Nanomedicine 2012;7:49-60

87. Allen TM, Cullis PR. Liposomal drug delivery systems: From concept to clinical applications. Adv Drug Deliv Rev 2013;65:36-48. 